\title{
KINERJA PEMERINTAH KAMPUNG \\ DALAM PENGELOLAAN ALOKASI DANA DESA (ADD) DI KAMPUNG NOHON DISTRIK PASSUE KABUPATEN MAPPI PROVINSI PAPUA
}

\author{
Oleh \\ Ucok Pardosi ${ }^{1}$, \\ Ermaya Suradinata ${ }^{2}$, Rossy Lambelanova ${ }^{3}$ \\ 1) Pemerintah Kabupaten Mappi \\ Program Magister Terapan Studi Pemerintahan Daerah Institut Pemerintahan Dalam Negeri \\ brianpardosi170484@gmail.com \\ ${ }^{2,3)}$ Institut Pemerintahan Dalam Negeri
}

\begin{abstract}
$T^{n}$ The performance of the Nohon Village Government in managing the Village Fund Allocation $(A D D)$ is considered to be less than optimal, this is due to the slow pace of apparatus resources, lack of understanding of technology and information as well as other supporting facilities and infrastructure that are still lacking.

This research is qualitatively related to organizational performance indicators, namely Productivity, Service Quality, Responsiveness, Responsibility and Accountability (Dwiyanto in Sudarmanto, 2015: 16) balanced with supporting factors and inhibiting factors and strategies in order to improve the performance of the Nohon Village Government using ASOCA analysis (Suradinata, 2013).

The results showed that the performance capacity of the Nohon Village Government was quite good, but there was a need for an increase in the quality of the Village Apparatus, besides that there was also a need for standard operating procedures regarding the implementation of Village Fund Allocation (ADD) management and the need to improve supporting facilities and infrastructure. Strategies that are also suggestions are motivation and work encouragement from the Village Head to his apparatus, the existence of standard operating procedures, technical guidance, and coordination between the Village Community Empowerment Service and the Village Government regarding the management of Village Fund Allocation (ADD), as well as providing work incentives to Village device.
\end{abstract}

Keywords: organizational performance, village fund allocation, ASOCA

\section{Abstrak}

$\mathrm{K}_{\mathrm{d}}^{\mathrm{in}}$ inerja dari Pemerintah Kampung Nohon dalam pengelolaan Alokasi Dana Desa (ADD) dianggap kurang maksimal, hal ini dikarenakan masih lambatnya sumber daya aparatur, kurangnya pemahaman tentang teknologi dan informasi dan juga sarana dan prasarana pendukung lainnya yang masih kurang.

Penelitian ini secara kualitatif terkait indikator kinerja organisasi, yaitu Produktivitas, Kualitas Layanan, Responsivitas, Responsibilitas dan Akuntabilitas (Dwiyanto dalam Sudarmanto,2015:16) diimbangi dengan faktor pendukung dan faktor penghambat serta 
strategi dalam rangka meningkatkan kinerja Pemerintah Kampung Nohon menggunakan analisis ASOCA (Suradinata,2013).

Hasil penelitian menunjukkan kemampuan kinerja Pemerintah Kampung Nohon sudah cukup baik, namun perlu adanya peningkatan kualitas dari Perangkat Kampung, selain itu juga perlu adanya standar operasional prosedur tentang pelaksanaan pengelolaan Alokasi Dana Desa (ADD) serta perlu adanya peningkatan sarana dan prasarana pendukung. Strategi yang juga merupakan saran yakni motivasi serta dorongan kerja dari Kepala Kampung kepada perangkatnya, adanya standar operasional prosedur yang dibuat, bimbingan teknis, dan koordinasi antara Dinas Pemberdayaan Masyarakat Kampung dan Pemerintah Kampung terkait pengelolaan Alokasi Dana Desa (ADD), serta pemberian insentif kerja kepada Perangkat Kampung.

Kata kunci: kinerja organisasi, alokasi dana desa, ASOCA

\section{PENDAHULUAN}

$\mathrm{D}$ esa adalah sekumpulan manusia yang hidup bersama atau suatu wilayah yang memiliki suatu organisasi pemerintahan dengan serangkaian peraturan-peraturan yang ditetapkan sendiri, serta berada di bawah pimpinan desa yang dipilih dan ditetapkan sendiri (Soemantri, 2013:3), namun keberhasilan yang ditunjukkan oleh tiap daerah Kabupaten/Kota dalam pengelolaan sumber daya yang ada, belum sepenuhnya berdampak pada kehidupan ekonomi masyarakat desa.

Hal ini terlihat dengan masih tingginya angka kemiskinan di desa yang menimbulkan ketimpangan ekonomi antara desa dan kota. Dalam berbagai aspek pembangunan, desa sering kali tertinggal jika dibandingkan dengan daerah kota seperti yang terjadi di Papua Kabupaten Mappi khususnya di Kampung Nohon Distrik Passue, maka dari itu pemberdayaan dari Pemerintah Daerah kepada masyarakat khususnya di wilayah Kampung Nohon memerlukan dukungan penuh sehingga dapat melaksanakan pembangunan dengan tepat sasaran. Dalam hal ini penulis sangat tertarik dengan melakukan penelitian tentang Kinerja Pemerintah Kampung Dalam Pengelolaan Alokasi Dana Desa (ADD) Di Kampung Nohon Distrik Passue Kabupaten Mappi Provinsi Papua.
Pada kenyataan yang terjadi di lapangan adalah kurangnya pemahaman tentang penggunaan Alokasi Dana Desa (ADD), tingkat pendidikan sumber daya aparatur di Kampung Nohon masih rendah dan ratarata pendidikan mereka hanya sampai di tingkat (sekolah dasar) SD, minimnya sarana dan prasarana pendukung yang menjadi penunjang dalam pengelolaan Alokasi Dana Desa (ADD) dan sebagian besar Distrik di Kabupaten Mappi menggunakan jalur transportasi sungai yang menghubungkan antara Distrik dan Kampung demikian pula sebaliknya antara Distrik dan Kabupaten, alat transportasi sungai yang sangat kurang, sehingga monitoring dan pengawasan perlu ada biaya operasional ekstra yang lebih dalam menjalankan tugas. Untuk menjangkau pengawasan pengelolaan Alokasi Dana Desa (ADD), pemerintah harus siap dengan biaya operasional (bahan bakar minyak) BBM untuk penggunaan transportasi Speedboat yang menggunakan Bensin 400 liter pulang pergi (PP), sebab jarak antara Distrik dan Kampung Nohon sangat jauh yang memakan waktu lamanya 7 (tujuh) jam perjalanan dan biaya yang dikeluarkan bisa mencapai Rp4.800.000,- (empat juta delapan ratus ribu rupiah) hanya untuk bahan bakar minyak (BBM) dengan harga per liter bensin mencapai Rp12.000,- (dua belas ribu rupiah) Hasil perjalanan dan pembiayaan ini bersumber dari data Kantor Distrik Passue. Sarana dan prasarana pendukung 
juga sangat kurang seperti halnya: Listrik, Jaringan Telkomsel, alat transportasi darat, gedung dan lain sebagainya yang menjadi faktor penghambat di Kampung Nohon.

Kinerja dari tim pengelolaan Alokasi Dana Desa (ADD) di Kampung Nohon masih belum optimal karena sumber daya manusia di kampung tersebut belum mampu dalam pelaksanaannya sehingga perlu ada pengawasan dari tingkat Distrik yang membantu Kampung tersebut dalam pengawasan. Alokasi Dana Desa (ADD) yang diberikan oleh Pemerintah untuk Kampung Nohon adalah Rp482.082.275 (Empat Ratus Delapan Puluh Dua Juta Delapan Puluh Dua Ribu Dua Ratus Tujuh Puluh Lima Rupiah) tahun anggaran 2018.

\section{KAJIAN PUSTAKA}

\section{Alokasi Dana Desa (ADD)}

Alokasi Dana Desa (ADD) merupakan salah satu aspek yang penting dari sebuah Desa sebagai pendorong untuk menjalankan program-program dari pemerintahan, termasuk di antaranya adalah program untuk menyejahterakan masyarakat di wilayahnya. Untuk menjalankan program pemerintahan, maka situasi yang perlu dilihat adalah jarak tempuh di lapangan, di mana alat transportasi sungai seperti Speedboat yang sangat efektif untuk sampai ke Kampung Nohon karena untuk sampai ke kampung tersebut semua harus ditempuh melalui jalur sungai dan tidak ada jalan darat. Jarak tempuh antara Kabupaten dan Kampung yang berjauhan demikian juga antara Distrik dan Kampung.

Good governance atau tata pemerintahan yang baik adalah pemerintahan yang sangat menyadari kegiatannya dalam etika pemerintahan dengan melibatkan berbagai elemen bangsa termasuk memahami keadaan dan kebutuhan masyarakat yang terus berkembang sangat dinamis. Oleh karena itu prinsip dasar tata pemerintahan dan peningkatan kinerja yang perlu diperhatikan antara lain mencakup delapan prinsip, yaitu: prinsip kepastian hukum, prinsip keterbukaan, prinsip akuntabilitas, prinsip profesionalitas, prinsip kebinekaan Negara Kesatuan Republik Indonesia (NKRI), prinsip pembudayaan kinerja yang baik dan benar, prinsip kepemimpinan yang berkarakter bangsa Indonesia dan prinsip nasionalisme dan patriotisme.

\section{Kinerja Organisasi}

Dalam penelitian ini penulis menggunakan alat analisis yang terdiri dari:

1. Produktivitas: dengan mengukur tingkat efisiensi, efektivitas pelayanan dan tingkat pelayanan publik dalam rangka mencapai hasil yang diharapkan;

2. Kualitas layanan: dengan mengukur kepuasan masyarakat terhadap layanan yang diberikan;

3. Responsivitas: dengan mengukur kemampuan organisasi untuk mengenali kebutuhan masyarakat, menyusun agenda dan prioritas pelayanan dan mengembangkan program-program pelayanan publik sesuai dengan kebutuhan dan aspirasi masyarakat;

4. Responsibilitas:menjelaskan/mengukur kesesuaian pelaksanaan kegiatan organisasi publik yang dilakukan dengan prinsip-prinsip administrasi yang benar atau sesuai dengan kebijakan organisasi;

5. Akuntabilitas: seberapa besar kebijakan dan kegiatan organisasi publik tunduk pada para pejabatpolitikyang dipiliholeh rakyat atau ukuran yang menunjukkan tingkat kesesuaian penyelenggaraan pelayanan dengan ukuran nilai-nilai atau norma eksternal yang ada di masyarakat atau yang dimiliki para stakeholders.

Berdasarkan lima dimensi di atas, maka penulis akan melakukan observasi (pengamatan) langsung di Kabupaten Mappi khususnya di Kampung Nohon Distrik Passue serta wawancara kepada 
pihak yang berkaitan dengan penelitian guna mengetahui sejauh mana kinerja yang dilakukan oleh Pemerintah Kampung Nohon dalam mengelola Alokasi Dana Desa (ADD).

1. Produktivitas

Konsep produktivitas tidak hanya mengukur tingkat efisiensi, tetapi juga efektivitas kinerja Pemerintah Kampung Nohon agar mencapai hasil yang diharapkan.

2. Kualitas layanan

Kualitas layanan cenderung menjadi penting dalam menjelaskan kinerja Pemerintah Kampung Nohon dalam mengelola Alokasi Dana Desa (ADD) Banyak pandangan negatif dari masyarakat mengenai kinerja karena ketidakpuasan masyarakat.

3. Responsivitas

Mengukur kemampuan kinerja Pemerintah Kampung Nohon untuk mengetahui kebutuhan masyarakat.

4. Responsibilitas

Menjelaskan atau mengukur pelaksanaan pengelolaan Alokasi Dana Desa (ADD) dengan prinsip-prinsip administrasi yang benar.

5. Akuntabilitas

Akuntabilitas digunakan untuk melihat seberapa besar kebijakan dalam penelitian ini, yaitu Pemerintah Kampung Nohon dengan kehendak masyarakat banyak dengan ukuran nilainilai atau norma eksternal yang ada di masyarakat atau yang dimiliki para stakeholders.

\section{Analisis ASOCA}

Dalam mendapatkan strategi penulis menggunakan analisis tata kelola pemerintahan yang baik dapat menggunakan metode analisis ASOCA, yaitu kepanjangan dari: ability (kemampuan), strength (kekuatan), opporttunities (peluang), culture (budaya) dan agility (kecerdasan) sebagai unsur yang penting dalam menemukan strategi pemecahan masalah, pengambilan putusan dan dapat dikembangkan dalam mengikuti perubahan, perkembangan zaman dan kebutuhan. Terminologi ASOCA dapat dijelaskan sebagai berikut.

- Ability (kemampuan)

Pemerintah Kampung Nohon harus mampu dalam mengelola Alokasi Dana Desa (ADD) agar tujuan sasarannya tepat kepada masyarakat.

- $\quad$ Strength (kekuatan, ketangguhan)

Dalam pengelolaan Alokasi Dana Desa (ADD), harus diperkuat dengan adanya Standar Operasional Prosedur (SOP) sehingga Pemerintah Kampung Nohon dapat menyelesaikan tugas sesuai dengan waktu yang ditentukan.

- Opportunity (peluang)

Banyaknya peluang yang diberikan kepada Pemerintah Kampung Nohon dalam rangka peningkatan kapasitas sumber daya aparatur guna meningkatkan kualitas kinerja.

- $\quad$ Culture (budaya)

Cara kerja Pemerintah Kampung Nohon harus lebih maju dari pada sebelumnya, sehingga mendapatkan hasil kerja yang lebih baik ke depannya.

- $\quad$ Agility (kecerdasan)

Kecerdasan dari perangkat Pemerintah Kampung Nohon harus lebih tajam karena kemampuan saja tidak cukup sehingga dalam mengelola Alokasi Dana Desa (ADD) lebih tepat sasaran.

Sinergitas elemen-elemen ASOCA sangat penting yang dapat dikelompokkan ke dalam lingkungan strategis internal dan eksternal yang dapat dibuat dalam bentuk matriks. 


\section{METODE PENELITIAN}

Penelitian ini merupakan upaya untuk memahami dan mendeskripsikan fenomena dan gejala-gejala yang terjadi terhadap Kinerja Pemerintah Kampung Dalam Pengelolaan Alokasi Dana Desa (ADD) Di Kampung Nohon Distrik Passue Kabupaten Mappi Provinsi Papua, termasuk upaya mengungkap dan mengadakan elaborasi tentang kemungkinan faktor-faktor yang berpengaruh terhadap tingkat kemajuan PemerintahKampungsertafaktorpendukung dan penghambat dalam pengelolaan Alokasi Dana Desa (ADD) menggunakan metode kualitatif dengan pendekatan induktif.

Untuk mengetahui tingkat keberhasilan dari Kinerja Pemerintah Kampung Dalam Mengelola Alokasi Dana Desa (ADD), maka ada lima teori kinerja organisasi, yaitu: produktivitas, kualitas layanan, responsitas, responsibilitas dan akuntabilitas. Untuk meningkatkan Kinerja Pemerintah Kampung Dalam Mengelola Alokasi Dana Desa (ADD) Di Kampung Nohon Distrik Passue Kabupaten Mappi Provinsi Papua, maka strategi yang diambil untuk digunakan dalam penelitian adalah metode Analisis ASOCA, yaitu: Ability/Kemampuan; Strength/Kekuatan, ketangguhan; Opportunity/Peluang; Culture/ budaya; Agility/Kecerdasan.

\section{HASIL DAN PEMBAHASAN}

Kinerja Pemerintah Kampung Nohon dalam pencapaian dapat dilihat dari tingkat kepuasan masyarakat kepada Pemerintah Kampung Nohon dalam pengelolaan Alokasi Dana Desa (ADD) untuk kemajuan pembangunan di Kampung Nohon.

Berdasarkan lima indikator untuk mengukur kinerja sebuah organisasi maka penulis melakukan observasi (pengamatan) langsung di Kampung Nohon Distrik Passue
Kabupaten Mappi serta melaksanakan wawancara kepada pihak yang berkaitan dengan penelitian guna mengetahui sejauh mana kinerjayang dilakukan oleh Pemerintah Kampung dalam pengelolaan Alokasi Dana Desa (ADD) di Kampung Nohon.

Kinerja Pemerintah Kampung Dalam Pengelolaan Alokasi Dana Desa (ADD) Di Kampung Nohon Distrik Passue Kabupaten Mappi Provinsi Papua

Produktivitas, Kepala Seksi Kesejahteraan Distrik Passue mengarahkan staf-staf kantor untuk memberikan bantuan ide-ide atau tenaga untuk Pemerintah Kampung Nohon memberikan pelayanan kepada masyarakat yang lebih baik. Kualitas Layanan, Pemerintah Kampung Nohon berupaya mengutamakan kepentingan pelayanan kepada masyarakat. Responsivitas, Dalam hal ini kebutuhan dan aspirasi masyarakat Kampung Nohon harus terpenuhi karena selama ini Kampung mereka sangat tertinggal dan karena itulah Pemerintah Kampung Nohon tetap berupaya bekerja dalam melaksanakan pembangunan di Kampung Nohon. Responsibilitas, Administrasi Kampung Nohon belum baik dikarenakan belum memahami penyusunan. Akuntabilitas, Dapat dilihat dari indikator akuntabilitas dengan melihat seberapa besar kebijakan dan kegiatan organisasi dalam hal ini kinerja Pemerintah Kampung Nohon selalu mengutamakan kepentingan/ kebutuhan masyarakat kampung sesuai dengan pendapat masyarakat kampung dalam pembangunan di kampung.

\section{Faktor Pendukung dan Penghambat Kinerja Pemerintah Kampung}

Faktor pendukung, yaitu kemampuan dari kinerja Pemerintah Kampung Nohon mengutamakan kepentingan melayani masyarakat dari pada kepentingan pribadi 
atau golongan tentunya ini akan memberikan hasil kerja yang maksimal kepada masyarakat. Faktor penghambat, yaitu faktor yang menghalangi atau menjadi penghambat dalam suatu pekerjaan sehingga menjadi tidak stabil atau tidak lancar serta tidak berjalan normal. bahwa faktor penghambat kinerja Pemerintah Kampung Nohon adalah kurangnya sarana dan prasarana, kurangnya pemahaman dan rendahnya tingkat pendidikan yang menunjang pekerjaan mereka sehingga membuat pelaksanaan pengelolaan Alokasi Dana Desa (ADD) menjadi terhambat.

\section{Strategi Mengatasi Faktor Penghambat Kinerja Pemerintah Kampung}

Ability (kemampuan): Dengan Adanya pendampingan dari Dinas Pemberdayaan Masyarakat Kampung (DPMK) Kabupaten Mappi. Strength (kekuatan, ketangguhan): Pemerintah Kampung Nohon harus lebih memahami apa yang diinginkan oleh masyarakat dengan pola pikir yang berbeda. Opportunity (peluang): Adanya ruang gerak dari Pemerintah Kampung Nohon dalam memberikan kesempatan kepada masyarakat untuk menyampaikan pendapat mereka demi kemajuan kampung. Culture (budaya): Masyarakat Kampung Nohon sangat puas dengan hasil kinerja Pemerintah Kampung Nohon. Agility (kecerdasan): Pemerintah Kampung Nohon lebih memahami dalam mengelola Alokasi Dana Desa (ADD).

\section{SIMPULAN}

Simpulan dalam penelitian ini bahwa kinerja Pemerintah Kampung Nohon dalam pengelolaan Alokasi Dana Desa (ADD) masih belum maksimal karena belum adanya pengarahan dari Dinas Pemberdayaan Masyarakat Kampung (DPMK)Kabupaten Mappi kepada Pemerintah Kampung tentang tata cara dalam mengelola Alokasi
Dana Desa (ADD) yang lebih baik lagi. Hal tersebut dilihat dari tingkat pendidikan dari Perangkat Kampung yang masih rendah serta sarana dan prasarana yang belum memadai. Dalam membuat pelaporan pertanggungjawaban penggunaan Alokasi Dana Desa (ADD) masih belum maksimal, karena Perangkat Kampung yang belum bisa menggunakan sarana komputer untuk membuat laporan sehingga mengharuskan mereka menggunakan jasa pengetikan di luar. Serta pendampingan sangat perlu sekali dalam mendampingi Perangkat Kampung guna tercapainya pengelolaan Alokasi Dana Desa (ADD).

\section{SARAN}

Adapun saran sebagai perbaikan untuk meningkatkan kinerja Pemerintah Kampung Dalam pengelolaan Alokasi Dana Desa (ADD) Di Kampung Nohon Distrik Passue Kabupaten Mappi Provinsi Papua yakni Produktivitas: Pemerintah Distrik Passue memberikan bantuan tenaga dan pikiran untuk memberikan pelayanan kepada masyarakat. Kualitas Layanan: Adanya usaha dari Pemerintah Kampung Nohon untuk memberikan pelayanan prima kepada masyarakat. Responsivitas: Pemerintah Kampung Nohon perlu menampung aspirasi masyarakat dan mendahulukan kebutuhan kampung. Responsibilitas: Dinas Pemberdayaan Masyarakat Kampung (DPMK) Kabupaten Mappi seharusnya memberikan pelatihan-pelatihan bagi Pemerintah Kampung Nohon agar mereka tahu tata cara penggunaan pengelolaan Alokasi Dana Desa (ADD) serta mereka pun tahu bagaimana cara pembuatan pelaporan pertanggungjawaban. Akuntabilitas: Mengutamakan pelayanan kepada masyarakat agar masyarakat puas dengan hasil kinerja Pemerintah Kampung Nohon. Sedangkan untuk mengatasi penghambat 
dan yang menadi faktor pendukung Faktor Pendukung: kinerja Pemerintah Kampung Nohon harus ditingkatkan lagi kemampuan serta pelayanan kepada masyarakat. Faktor Penghambat: Pemerintah Kampung Nohon harus terlebih dahulu melengkapi fasilitas utama kampung agar ke depan pada saat bekerja tidak kesusahan lagi. Adapun strategi ASOCAdalammengatasihambatan antaralain Ability (kemampuan): Dinas Pemberdayaan Masyarakat Kampung (DPMK) Kabupaten Mappi harus memberikan pendampingan agar Pemerintah Kampung Nohon dapat bekerja. Strength (kekuatan, ketangguhan): Sebagai Perangkat Kampung, harus bisa memenuhi yang diinginkan oleh masyarakat. Opportunity (peluang): Agar Kampung Nohon lebih maju, maka Pemerintah Kampung Nohon harus menampung pendapat dari masyarakat. Culture (budaya): Perlu ditingkatkan lagi hasil kinerja Pemerintah Kampung Nohon agar masyarakat lebih puas. Agility (kecerdasan): Ke depan Pemerintah Kampung Nohon harus lebih pandai dalam mengelola Alokasi Dana Desa.

\section{DAFTAR PUSTAKA}

Arikunto Suharsimi, Prosedur Penelitian, Jakarta: Rineka Cipta 2010.

Dwiyanto, A. Reformasi Birokrasi Publik di Indonesia, Cetakan Pertama, Yogyakarta: Galang Printika.2002

Effendy Khasan, Memadukan Metode Kuantitatif dan Kualitatif, Bandung: CV. Indra Prahasta, 2010.

Kasim, Azhar, Pengukuran Efektivitas Dalam Organisasi, Jakarta: Lembaga Penerbit Fakultas Ekonomi Universitas Indonesia, 1993.

Keban Yeremias, Enam Dimensi Strategis Administrasi Publik Konsep Teori dan Isu, Yogyakarta: Gava Media 2004.

Ming, Seri Manajemen Sumber Daya Manusia (Kinerja/Performance), Jakarta: Cetakan
Keempat, PT. Elex Media Komputindo, 1993.

Ruky, Ahmad, Sistem Manajemen Kinerja, Jakarta: Gramedia Pustaka Utama 2002

Rusidi, Memadukan Metode Kuantitatif dan Kualitatif, Bandung: Cv. Indra Prahasta 2010.

Simangunsong Fernandes, Metodologi Penelitian Pemerintahan, Bandung: Cv. ALFABETA 2016.

Soemantri Bambang Trisantono, Pedoman Penyelenggaraan Pemerintahan Desa, Bandung: Fokusmedia 2011.

Sudarmanto, Kinerja dan Pengembangan Kompetensi SDM, Yogyakarta: Pustaka Pelajar 2015

Sudarmanto, S.I. P., MSi. Kinerja dan Pengembangan Kompetensi SDM. Yogyakarta: Pustaka Pelajar.., 2009

Sugiyono, Metode Penelitian Kuantitatif, Kualitatif dan R\&D, Bandung: Cv. ALFABETA 2013.

Supriatna, tjahya, Sistem Pemerintahan Desa, Bandung: Cv. Indra Prahasta 2010.

Suradinata Ermaya, Analisis Kepemimpinan Strategi Pengambilan Keputusan, Jatinangor: Alqaprint 2013.

Surmayadi I Nyoman, Perencanaan Pembangunan Daerah Otonom dan Pemberdayaan Masyarakat, Jakarta: Citra Utama 2005.

Wahjudin Sumpeno, Perencanaan Desa Terpadu, Banda Aceh, Reinforcement Action and Development, 2011.

\section{Peraturan Perundang-Undangan}

Undang-Undang Nomor 21 Tahun 2001 tentang Otonomi Khusus bagi Provinsi Papua.

Undang-Undang Nomor 35 Tahun 2008 tentang Penetapan Peraturan Pemerintah pengganti Undang-Undang Nomor 1 Tahun 2008 tentang Perubahan atas UndangUndang Nomor 21 Tahun 2001 tentang Otonomi Khusus bagi Provinsi Papua.

Undang-Undang RI Nomor 6 Tahun 2014 tentang Desa.

Undang-Undang Nomor 23 Tahun 2014 tentang Pemerintahan Daerah. 
Peraturan Pemerintah Nomor 43 Tahun 2014 tentang Desa.

Peraturan Pemerintah Nomor 17 Tahun 2018 tentang Kecamatan.

Peraturan Bupati Nomor 46 Tahun 2018 tentang Tata Cara Pembagian dan Penetapan
Rincian Bantuan Keuangan Kepada Pemerintah Desa Kabupaten Mappi Tahun Anggaran Tahun 2018.

Peraturan Bupati Nomor 17 Tahun 2019 tentang Pedoman Pembentukan Susunan Organisasi dan Tata Kerja Pemerintah Kampung. 